\title{
DI MEM Û ZÎNÊ DE HUNERÊN MECAZÎ
}

\section{Osman Aslanoğlu**}

\section{Kurte}

Ehmedê Xanî, yek ji helbestvanên navdar ên wêjeya Kurdî ya klasîk e. Wî ji bo Kurdî berhemên pir hêja dane. Mem û Zîn berhema wî ya herî girîng e û ew ji gelek alîyan ve xwedîyê nirxeke bilind e. Mesnewîya Mem û Zîn'ê berhemeke evînî ye û ji bo îsbata qabiliyeta zimanê Kurdî ya di qada wêjeyê de hatiye nivîsîn. Bi vê armancê ji bo nîşandana asta zimanê Kurdî, Xanî ew berhem bi gellek hunerên wêjeyî xemilandiye. Mijara xebata me jî cureyeke hunerên wêjeyî ye. Em ê li ser hunerên mecazî bisekinin ku ev cure ji çar cureyên hunerî ye. Hunerên mecazî têkildarê şibandinê ne. Di hunerên mecazî de bi awayên cuda şibandin heye. Di vê çarçoveyê de jî em ê li ser 6 hunerên mecazî bisekinin. Tespîtkirina wan huneran û nasîna wan, ji bo têgihîş̧ina nirxa vê berhemê dê bibe pêlikek.

Bêjeyên Kilîdî: Mem û Zîn, Ehmedê Xanî, Hunerên Wêjeyî, Mecaz, Kurdî METAPHORICAL ARTS IN THE MEM AND ZIN

\begin{abstract}
Ahmedi Khani is from famous poets of classical Kurdish literature. He has given very precious works for Kurdish. Mem and Zin which are the most important work of Khani has a great value in many ways. Mem and Zin masnavi is a love work; but it has been written to prove the ability of Kurdish in literature field. For this purpose Khani has adorned that work with so many literary arts to show the level of Kurdish language. Our study subject is a kind of literary arts too. We are going to put emphasis on metaphorical arts which are one of the four literary kinds. There is simile in different forms in metaphorical arts. In this context we are going to put emphasis on six figurative arts. Revealing these works and recognizing them will be a step to understand the value of this work.
\end{abstract}

Keywords: Mem and Zin, Ahmed-i Khani, Literary Arts, Metaphor, Kurdish

\footnotetext{
* Ev gotar, ji beşeke pêş̧eşîya kongreya navnetewî ya zanistên civakî ku ji aliyê Weqfa Şakiyatê ve di 14-17 Îlon 2017an de hatiye lidarxistin, hatiye sererastkirin û amadekirin.

Makale Gönderim Tarihi: 30.11.2018, Kabul Tarihi: 30.04.2019

Doi: $10.26791 /$ sarkiat.490548

** Dr. Öğr. Ü., Dicle Üniversitesi, Edebiyat Fakültesi, Doğu Dilleri ve Edebiyatları Bölümü, Kürt Dili ve Edebiyatı Anabilim Dalı, aslanogluosman@gmail.com.
}

ORCID ID: orcid.org/0000-0001-6534-3125 


\section{DESTPÊK}

Hunerên ku di helbestan de tên bikar anîn, dikevin nav mijara belaxat û xweş gotinê. Di mijara xweşgotinê de jî bêjeyên fesahet û belaxetê derdikevin pêş. Fesahet tê wateya derketin, xûyabûn û vekirîbûnê. Bi pênaseya hunernasan, tevî dûrbûna jî kêmasîyan eşkerebûna gotinê ye(Harbî, 2011, 11). Belaxat di ferhengê de tê wateyên wek "gihîştin, têgihîştin, mezin bûn (Akdemir, 1999, 9). Belaxat, wek têgeh tê vê wateyê: "gotina fikrekî di cih û dema keys de bi awayekî rast û bibandor e. Lê bi şerta ku fesîh (ji kêmasîyên dengî û wateyî dûr) be"(İsen û ên din, 2016, 28). Yanê gotina peyva fesîh bi gora zeman û zemîn û rewşê. Xencî vê ji bo belaxetê gelek tarîf hene(Çağmar, 2013, 14).Di Erebî de ji "Hunerên wêjeŷ̀" re dibêjin "Belaxat", di Farsî de dibêjin "Araye". Di Kurdî de ciwankarî jî tê gotin.

Di pirtûkên zimannasîyê de teşenasî, watenasî, bêjenasî û rêznasî(rêzkirina bêjeyan) beşên bingehîn in. Di pirtûkan de hunerên wêjeyî jî di bin heman sernavan de tên dabeş kirin. Yanê hin huner ji alîyê wateyê ve, hin huner ji alîyê gotinê ve, hin huner ji alîyê rêzkirinê ve û hwd. tên bikaranîn. Di wêjeyê de cureyên huneran, bi piranî li ser du beşan tên veqetandin (Selçuk û ên din, 2015, 31-33). Ew jî Bedî‘ û Beyan in. Hinek jî wan dikin sê beş. Beşa sêyemîn jî "Meanî̀" ye. (Külekçi, 2011, 9) Di bin van beşan de hunerên wêjeyî bi piranî bi çar sernavan tên dayîn:

1-Hunerên girêdayî bi mecazê/teşbîh ve

2-Hunerên girêdayî bi wateyê ve

\section{3-Hunerên girêdayî bi peyvê ve}

\section{4-Hunerên girêdayî bi herf û nivîsê ve}

Di mesnewîya yekem(Adak, 2014, 256) a Kurdî Mem û Zînê de ev hemû cure huner, bi rehetî tên dîtin. Ji ber ku Xanî ev berhem bi armanceke taybet nivîsandiye. Xanî, ji bo ku karekî baş derxîne holê demeke dirêj xebitîye û Mem û Zîn di pênc salan de qedandiye(Bnr. Açıkgöz, 2012, 5). Bi zimanê Ehmedê Xanî, ev mesnewî, ji bo ku kes nebêje "Kurd ji evînê fehm nakin û nezan in..." hatiye nivîsandin (Kurdo, 1992, 111; Sağniç, 2014, 395).

Xanî di her rist û malikê de gellek hunerên wêjeyî bi hev re bi kar anîne. Lê em ê di vê xebatê de li ser beşa yekemin, hunerên mecazî bisekinin. Cureyên vê beşa mecazê, wek taybetiyeke hepvar, xwedîyê şibandinê ne. Yanê hunerên vê beşê her çiqas ji hev cuda bin jî di hemûyan de şibandin heye. Lê girêdayê taybetîyên xwe ji hev vediqetin. Di vê beşê de em ê li ser 6 heb hunerên mecazî ên bingehîn bisekinin:

\section{Mecaza Mursel û Mecaza Eqlî}

Mecaz peyveke Erebî ye ku ji peyva "caze" bi wateya "derbasbûn"ê hatiye wergitin(Cîhanî, 2013, 42). Cih û dema ku tê re derbas dibin. Rê û derbasok. Bikaranîna bêjeyê di wateya xwe ya nerast de(Akdemir, 1999, 229; Curr, 1373, Cilt II, 1825). Di vê hunerê de armanca helbestvên, zêdekirina xweşikî, balkêşî û zîndîbûna gotinê ye. Mecaz, alîkarîya çêkirin û derketina teşbîh, îstîare, kînaye û hwd. dike(İsen û ên din, 2016, 330). Di hunera mecazê de, wateya ku tê armanc kirin, li hember wateya rasteqîn cih digire. Wateya rasteqîn jî wateya yekemîn e ku tê hişê mirov. Di gotinê de divê îşareteke lefzî an halî hebe ku meriv zanibe ku wateya rasteqîn nehatiye armanc kirin(Akdemir, 1999, 230).

Di zimên de têgeha mecazê, du cure ne:

a) Mecaza luxewî 


\section{b) Mecaza eqlî}

Mecaza luxewî, tevî qerîneya mani‘e ji sedem eleqeyekê, bikaranîna bêjeyê, ne di wateya wê de ye. Gava ku eleqe teşbîh be, ji vê mecazê re "îstîare" tê gotin(Teftezanî, 2005, 57, 63). Gava ku eleqe, ne teşbîh be, "mecaza mursel" tê gotin. Lê mecaza eqlî(îsnadî), nîsbetkirina lêkerê yan jî nîsbetkirina tiştên ku ji lêkerê hatine dariştin bi bal tiştekî ku eleqeya wî tiştî bi wan ve tuneye(Çağmar, 2013, 45).

Em niha li ser van her du cureyan bisekinin û mînakan bidin:

\subsection{Mecaza Mursel}

Wek me li jor got di vê hunerê de têkilî û eleqeya şibandinê tuneye. Bi hin têkilîyên din peyvek di cihê peyveke din de bikar tê. Ev têkilî dora 13 heban in. Têkilîyên wek: cuzkull, hâl-mahal, lazim-melzûm, sebeb-musebbeb, taybet-giştî, mâkân-mâyekûn, cins, qewm û merivatî, sifet-mewsûf, nêzikayî, dijberî, şibîn, endamî/uzwîyet(Değirmençay, 2014, 151-161). Em li ser hinek mînakan bisekinin:

\section{Rabit ji me jî cihanpenahek}

Peyda bibitin me padîşahek (196)*

Cîhanpenah, tê wateya stargeh, piştgirê mirovên cîhanê(Enverî ve diğerleri, 1381, 3: 2238). Li vir padişahê ku ji bo Kurdan tê xwestin tê terîfkirin. Ew padişah ji alemê re dibe penah yanê stargeh û piştgir. Li vir her çiqas Xanî, "cîhan" gotibe jî mebest jê "mirovên li cîhanê" ne. Di vir de jî̀ mecaza mursel a bi têkilîya hâll-mehell heye. Yanê cih hatiye gotin lê kesên di wir de hatine qesdkirin.

\section{Te 'yîn bib̂̂ye ji bo wîtextek}

\section{Zahir vedibû ji bo me bextek (203)}

Di vê mînakê de Xanî behsa daxwaza hebûna padişahekî dike û dibêje ku eger padişahekî me Kurdan jî hebûya û ew kes xwedîyê textekî bûya, bexta me jî vedibû. Li vir mebest ji têxt, hakimîyet û serdarîya wî ye. Li vir têkilîya sebeb-musebbeb heye. Ji ber ku text dibe sedema hakimîyetê û wê temsîl dike.

\section{Yaqûti bi mohriyan guhorîn}

\section{Elmasi bi şûşeyê bilûrîn (583)}

Zîn û Sitî di Newrozê de gustîlkên Mem û Tacdîn bi ên xwe re diguherînin. Xanî dema behsa taybetîyên wan gustîlkan dike behsa madena kevirê wan dike. Dibêje gustîlkên bi yaqût bi gustîlkên bi morî re, gustîlkên bi elmas bi gustîlkên bi camî re guhêrandin. Yanê Xanî gotiye yaqût, lê mebesta xwe gustîlka bi yaqût e. Bi vî awayî eslê tiştekî hatiye gotin, tiştên ku pê çêbûye hatiye qesdkirin.

Em şêr in $\hat{u}$ ew(bi)xwe du xezal in

Pirr 'eyb e ku em ji dest binalin (628)

Tacdîn piştî ku ji mestîya dîtina hezkirîya xwe şîyar dibe, ji Mem re dibêje ku ew bixwe wek şêr in, şerm e ku ji destê hezkirîyên xwe wisa binalin. Li vir nalîna ji destê wan hatiye gotin. Lê mebest ne destê wan e. Kirinên şexsê wan in. Yanê Tacdîn û Mem ji

\footnotetext{
* Me ji bo malikan ev pirtûk bikar anî: “Açıkgöz, Namık, Ehmedê Xanî Mem û Zîn, Kültür ve Turizm Bakanlığı, Ankara, 2012.
} 
ber kirinên şexsê wan ketine wî halî. Bi vî awayî em dikarin bêjin ku bêjeya "dest" hatiye gotin, lê şexs hatiye qesdkirin. Yanê cuz hatiye gotin, kull hatiye qesdkirin.

\subsection{Mecaza Eqlî}

Wek ku me li jor got di mecaza eqlî an jî îsnadî de lêkerek li ser tiştekî tê gotin ku eleqeya wî bi wê lêkerê tuneye. Ji bo vê jî em mînakekê bidin:

\section{Sazan mirî heyy kirin wekî Sûr}

Kûs $\hat{u}$ def $\hat{u}$ kerrenay naqûr (995)

Dema ku Mîr qebûl dike ku Sitîyê bide Tacdîn, amadekariyên şahîyê tên kirin. Saz û def lêdikevin û bi coşa wan sazan, herkes kêfxweş dibe. Dengê van sazan ewqas xweş bû ku wek ku mirî jî radikirin. Di vir de lêkera hey kirinê ji bo sazan hatiye gotin. Saz nikarin mîrîyan sax bikin lê mirovan karin kêfxweş bikin. Ji ber vê li vir eleqeya sebebîyetê heye.

\section{Teşbîh}

Teşbîh, di ferhengê de "şibandina tiştekî bi tiştekî din" e. Nîşandana têkilîya tiştekî bi tiştekî din re di wesfekê de ye(Ekkawî, 1996, 224). Teşbîh an şibandin, ji bo vegotina taybetîya tiştekî an bûyerekê bi awayekî baştir, bikaranîna tiştekî din e. Yanê helbestvan tiştekî bi alîkarîya tiştekî din dide fehm kirin(Aydın, 2014, 113). Ev huner, di zanista belaxatê de xwedîyê cihekî girîng e. Wateyên dûr û razber, bi alîkarîya vê hunerê, nêzî heşê mirov dibin(Akdemir, 1999, 340).

Teşbîha di navbera xweza û mirovan de carinan ji aliyê xwezayê ve ber ve mirovan, carinan ji mirovan ber ve xwezayê û carinan jî di navbera tiştên xwezayî de tê kirin(Bnr. Aydın, 2014, 116-118). Navên endamên laşên mirovan, bi veguhastina ser tiştên di xwezayê de, wateyên nû nîşan didin. Ji van re veguhastina biwêjên mirî jî tê gotin.(Aydin, 2014, 116)

Di şibandinê de 4 alî hene:

1-Tiştê ku dişibe

2-Tiştê ku bi wê tê şibandin

\section{3-Alîyê şibandinê}

\section{4-Daçeka şibandinê}

Du xalên dawî carinan dibe ku neyên bikar anîn jî(Akdemir, 1999, 340). Dema meriv li mînakên Mem û zînê dinêre dibîne ku şibandin bi çend awayan hatine çêkirin. Eger em van dabeş kin, em dikarin bi awayê beşên li jêr ji hev veqetînin:

\subsection{Bi riya "kirde" û "pêveber"ê:}

Di vê beşe de hevok wek ku du beş in. Di beşa yekê de tiştê ku tê şibandin heye û wek kirde ye, di beşa duduyan a hevokê de tiştê ku pê hatiye şibandin heye û ew jî wek pêveber e. Yanê her du bêje jî hene. Xala balkêş di vê beşê de ew e ku daçeka şibandinê nayê bikar anîn. Rasterast tiştekî wek tiştekî din qebûl dike:

\section{Ey şukrê te cewhera zebanî}

W'ey zikrê te seyqela cenanî (37)

Vê mînaka jor ger em bi awayekî sivikkirî bêjin wiha dibe:

Şukr, cewher e.

Zikr, seyqel e. 
Ango "şukr wek cewherekê ye" î "zikr jî wek seyqelê ye".

\section{'Husna te ye zîneta 'hebîban}

Reşka te ye xîreta reqîban (56)

Di vê mînakê de jî husn û zînet li alîyekî, reşk û xîret jî li alîyê din bi hev ve hatine şibandin. Hevoka vekirîtir wiha dibe:

Husn, zînet e

Reşk, xîret e

Ango "husn, wek zînetê ye" û "reşk jî wek xîretê ye".

Çend mînakên din jî wiha ne:

Em, şêr in $\hat{u}$ ew (bi)xwe du xezal in

Pir 'eyb e ku em ji ber binalin (628)

Kur, ayîneyê cemalê zat in

Keç mezherê pertewê sifat in (699)

Di mînakên jor de jî cînavk hatiye bikar anîn û dibêje "em wek şêran in" , "ew wek xezalan in" û "kur wek ayîne ne".

Carinan heman kirde û pêveber bi şeklê berevajî dikarin werin. Yanê hevoka bêrist tê bikaranîn:

Genc î tu di nêv tilismê 'alem

Kenz î tu 'eyan ji ismê adem (12)

Di mînaka jor de hevoka bingehîn ev beşa reşkirî ye ku ji kirde û pêveberê pêk tê, lê cihên xwe guherandine. Şeklê rast ê hevokê wiha ye:

"Tu genc $\hat{\imath}$ " $\hat{u}$ "Tu kenz $\hat{\imath}$ ". Di van hevokan de şibandin heye. Ger em bi daçekan hevokê temam bikin wiha dibin: "Tu wek genc $\hat{\imath}$ " $\hat{u}$ "Tu wek kenz $\hat{\imath}$ ". Bi vî awayî jî teşbîh hatiye kirin.

\subsection{Bi rîya ravek û îzafeyê:}

Di vê beşê de du bêje bi alîkarîya qertafên veqetandekan bi hev ve tên girêdan û ravek tê çêkirin. Di van ravekan de bi piranî bêjeya yekê, tiştê ku pê tê şibandin e, bêjeya duduyan jî tiştê ku tê şibandin e. Yanê armanca helbestvan di şibandinên wiha de bêjeya duyem e û li ser girîngîya wê disekine. Ev cure jî di mesnewîya Xanî de gellek in.

Şûrê hunera me bête danîn

Qedrê qelema me bête zanîn (197)

Di vê mînakê de şûr û huner bi hev ve hatiye girêdan û ravek çêbûye. Lê li vir Xanî li ser girîngîya hunerê disekine û huner, bi şûr ve hatiye şibandin.

Ger em vê hevokê jî hêsan û bi awayekî kin binivîsin, wiha dibe:

"Huner wek şûr e."

Ez mame di hikmeta Xwedê da

Kurmanc-i di dewleta dinê da (216) 
Di vir de jî dinya, bi dewletê ve hatiye şibandin. Xanî dibêje ev dinya wek dewletekê ye û Kurd jî tê de ne. Lê çima bê par mane. Ger vê hevokê jî em ji hev vekin, em ê şibandineke wiha bibînin:

"Dinya wek dewletê ye".

\section{Wan girtî bi şîtrî şehrê şohret}

Tesxîr kirin biladê himmet (218)

Di mînakeke din de Xanî di malikekê de du teşbîhan dike. Di rista yekem de şehr û şohret, di ya duyem de jî bîlad û hîmmet hatine şibandin. Di raveka yekem de Xanî dibêje ku "şohret mîna bajarekî ye" û xelkê ew bajar bi şûr bi dest xistiye. Li vir Xanî dibêje ku xelkê, bajar bi hêza xwe bi dest xistiye. Lê ew bajar jî şohret e. Yanê kî hêdar be ew navdar dibe û dibe xwedîyê welatê xebatê. Ger em vê ravekê ji hev vekin, wiha dibe:

Şohret, wek bajar e.

Hîmmet, wek welat e.

Mîrim tu here bibeje Zînê

Mem suhtiyê agirê evînê(1981)

Li vir jî "agir" û "evîn” bi hev ve hatine şibandin. Mem jî bi vî agirî, yanê bi evînê şewitîye.

\subsection{Bi qertafa "ji":}

Ev cure teşbîh, bi alîkarîya qertafa "ji” çêdibe. Daçek tê navbera her du bêjeyên teşbîhê. Qertafa “ji”", par û parçeyê nîşan dide. Xanî gellek bêje bi vî awayî anîne. Di van şibandinan de carinan bêjeya yekê dişibe a duyem, carinan a duyem dişibe a yekem. Meriv dikare ji bo ku baştir fehm bike, di şûna qertafa "ji”"yê de daçeka "wek" bîne:

Ebrû ji kemanê qewsê eflak

Mujgan bi guman ji sehmê semmak (402)

Xanî dema behsa nasandina Zîn û Sitîyê dike û li ser xweşikiya wan disekine gellek şibandinan dike. Di heman mijarê de malika jor tê. Di vê malikê de di rista yekem de Xanî "ebrû" û "keman"ê dişêbîne hev. Di vê şibandinê de birûyê yarê wek kevan hatiye hesibandin. Di rista duyem de jî "mujgan" an "bijang", wek "sehm" an "tîr" hatiye fikirîn. Ger em van hevokan jî bi awayekî vekirî binivîsin, wiha dibin:

Ebrû wek keman e.

Mujgan wek sehme.

Şekker ji lebêd-i yek revandin

Sorgul ji ruxêd yek civandin (1085)

Di vir de cihê bêjeyan berevajî be jî şibandin hatiye kirin. Lêv wek şêkir in, rû jî wek gulên sor in.

\section{Bi daçekên şibandinê:}


Cureyeke din a şibandinê ku Xanî bikar anîye bi qertafên şibandinê tê çêkirin. Ev qertaf wekhevbûn û şibînê nişan didin. Ji bo çêkirina vê şibandinê qertafên "wek, mîna, sifet, misal, şebîh...." tên bikar anîn. Daçekên ji bilî "sifet"ê, tên pêşiya bêjeyê, lê bêjeya "sifet"ê tê dawîya bêjeyê:

\section{Herçend Sitî wekî qemer bû}

\section{Zîn mihresifet ziyade ter bû (416)}

Di vê mînakê de bi awayekî eşkere daçeka "wekî" ketiye navbera Sitî û qemerê; Xanî şibîna Sitîyê ya bi heyvê ve nişan dide. Ango dibêje ku "Sitî mîna heyvê xweşik bû". Di rista duduyan de jî behsa Zînê dike û bi daçeka "sifet"ê, dişêbîne rojê. "Wekî" di navbera bêjeyan de ye, lê "sifet", piştî bêjeya ku pê hatiye şibandin hatiye.

Sitî + wek̂े + qemer

Zîn + mêhr + sifet $=$ Zîn wekî mêhr(roj)

\section{Weqtê weku nû 'erûsê Xurşîd}

\section{Neh qubbe mîsalê camê Cemşîd (945)}

Dema biryara zewaca Sitî û Tacdîn tê dayîn, Sitîyê û Zînê ji bo dawetê dixemilînin. Xanî dema dest bi behsa vê beşê dike dibêje roj mîna bûkekê xweşik û ezman jî mîna qedeha Cemşîd ronî bûn û dibiriqîyan. Roj û ezmên, xweşikîya wan zêdetir dikir û rûyê her tiştî mîna zêr dibiriqand. Di malika jor de daçekên weku û misale ji bo şibandinê hatine bikar anîn. Awayê çêkirinê li jêr xûya ye:

Roj + weku + nû'erûsê

Neh qubbe + misalê + camê Cemşîd

Daçeka şibandinê dikare li cihekî dûr ji bêjeya yekem jî were. Di navbera bêjeyên şibandinê de lêker an hêmaneke din a hevokê dikare were:

\section{Ez mayîme her wekî Zuleyxa}

\section{Bê Yûsif û bêmirad $\hat{u}$ me 'wa (1858)}

Wek ku xuya dike bêje ketine navbera bêjeyên şibandinê. Bi van cureyan Xanî di şibandinê de gelek rêbazên cuda bikar anîne.

\section{3. Îstî́are}

Wateya wê ya bêjeyî, emanet girtin û deyn standina tiştekî ye. Lê îstîare di têgehê de tevî hebûna qerîneyekê ku maniê îradeya wateya heqîqî ye, bikaranîna bêjeyê an jî hevokê, di wateya xwe ya ne eslî de(Çağmar, 2013, 187). Yanê bikaranîna bêjeyekê di wateya wê ya nerast de (Değirmençay, 2014, 167). Bêje di wateya xwe ya rast de bikar nayê, ji ber ku îşareteke ku wateya wê ya nerast nîşan dide heye(Akdemir, 1999, 163). Yanê ev mecazek e ku bi şibandinê re têkildar e(Musahib, 1380, 128). Armanca vê hunerê şibandin e.

Di îstîareyê de du cure hene: vekirî û girtî.

\section{1. Îstiareya vekirî:}

Ji vê hunerê re îstîareya musarraha jî tê gotin. Di îstîareya vekirî de tenê tiştê ku pê hatiyê şibandin, tê gotin; tiştê ku dişibe nayê gotin(Ruhullah, 1394, 64):

\section{Ayîne te çêkirin mukerrer}


Husna xwe di wan te kir musewwer (70)

Di destpêka Mesnewîyê de Xanî wek hemû mesnewîyan pesna Xwedê dide, şukra xwe dike û tiştên ku Xwedê bi hîkmet li dinyayê çêkirine dibêje. Ji bo hebûnên li dinyayê ku Xwedê xweşik afirandine "ayîne" dibêje. Yanê Xanî hemû çêkirîyan wek ayîne qebûl dike. Li vir ji ber ku "ayîne" hatiye gotin, lê tiştê ku bi ayîneyê hatiye şibandin nehatiye gotin, hunera îstîareya hatiye bikar anîn.

\section{Ez dê çi bibêjim ey şehînşah}

Wessafê te ye kelamê Ellah (153)

Xanî di destpêka mesnewîyê de pesna pêxember (a.s.w) dide û di şûna ku navê wî bêje, rasterast wek "şah" bi nav dike. "Şehînşah", bêjeya ku pê hatiye şibandin e û li vir hatiye nivîsandin, lê "pêxember" nehatiye gotin. Ji ber vê ev dibe îstîareya vekirî.

\section{Ev gurgê le'înê bedserencam}

Jêkra biketin me şubhê exnam (185)

Xanî di destpêka mesnewîyê de di malikeke din de dîsa behsa pesna pêxember dike û halê xwe yê gunehkar ji bo şefaata wî vedibêje. Xanî, wiha tîne zimên ku şeytan bi me dilîze û em bêçare ne. Li vir Xanî, ji bo șeytên, navê "gurgê leîn" bikar aniye, ango "şeytanê bi le "net". Ji ber ku şeytan nehatiye gotin, tenê bêjeya ku pê hatiye şibandin, hatiye bikar anîn. Bi vî şeklî îstîareya vekirî derdikeve holê.

\section{Safì şemirand vexwarî durdî}

\section{Manendê durê lisanê Kurdî (238)}

Safî, tiştê pak e û li vir di cihê zimanên serdest û navdar de ye. Durd jî ew tişt e ku di bin rûn, şerab û tiştên wek wan de dimîne(Huseynî, - , 654). Mebest ji vê jî zimanê Kurdî ye. Xanî ji bo xwe dibêje ku min şeraba pak û paqij venexwar, ez çûm û min binê qedeha nerind û nepak vexwar. Li vir "durd" ji bo Kurdî hatiye gotin û pê hatiye şibandin. Ji ber ku tenê "durdî" hatiye nivîsandin, ev dibe îstîareya vekirî.

\section{Çi b'kim ku qewî kesad e bazar}

\section{Nînin ji qumaşî ra xerîdar (253)}

Dîsa Xanî Kurdî şibandiye qumêş û dibêje ji bo vî qumaşî û cawî, muşterî tunene. Yanê kes, Kurdî naxwaze. Li vir jî tenê qumaş hatiye gotin û Kurdî nehatiye gotin.

Ev name eger xirab e, ger qenc

Kêşaye me wî digel dused renc (337)

Name, ji bo berhema Mem û Zînê hatiye gotin. Lê navê berhemê nehatiye dayîn. Yanê dibêje ev pirtûk, xerab be jî, baş be jî, min pê pir zehmet kişandine. Li vir jî berhem bir nameyê hatiye şibandin.

\section{Fîl'hal ewan du afitaban}

\section{Dil çûyeve bal du mahitaban (751)}

Du afitab, du roj in, du mahîtab jî du heyv in û ji bo Sitî û Zînê, Mem û Tacdînê hatine gotin, lêbelê Xanî behsa navê wan nekiriye. Tenê bêjeyên ku ew kes dişêbin, di malikê de hene. Yanê Xanî bi vê malikê dibêje "hema ew keçik, bûne evîndarê wan lawikan".

Em çend mînakên din jî bidin:

Lê min ji rezan nekir temettu“

Manendê dizan bikes tetebbu '(339) 


\section{Ev meywe eger ne abdar e}

Kurmanci ye ev qeder li kar e (343)

\section{2. Îstiareya girtî:}

Îstîareya meknîye jî tê gotin. Di teşbîhê de "meşebbehun bih"(ê ku tiştek bi wê ve tê şibandin) tê hezfkirin û tenê "muşebbeh"(ê ku tê şibandin) tê gotin(Olgun, 1936, 56). Bêjeya ku tişt pê hatiye şibandin, bi awayekî eşkere nayê gotin. Tenê tiştekî ku wê bêjeyê tîne bîra mirovan an unsûreke têkildarê wê tê gotin. Ji du alîyên şibandinê, tenê tiştê ku dişibe tê dayîn û bêjeya ku pê tê şibandin bi awayekî eşkere nayê gotin(Saraç, 2013, 25).

\section{Sersebz $\hat{\imath} \hat{u}$ tazeberg $\hat{u}$ bar $\hat{\imath}$}

\section{Evçende çi hestiran dibarî? (1219)}

Di vir de hatina hêstiran ji çavan, wek barîna baranê hatiye fikirîn. Wê demê meriv dikare bêje ku hêstir bi baranê hatine şibandin. Yanê şibandin di navbera hêstir û baranê de ye. Li vir taybetîyeke baranê hatiye gotin û îşaretek ji bo fehmkirina wê teşbîhê heye, lê navê baranê nehatiye gotin. Ji ber vê li vir hunera îstîareya girtî heye.

Dîtin xwe paçebend $\hat{u}$ zengil

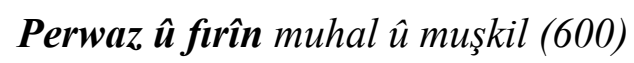

Mem û Tacdîn, ji dîtina hezkirîyên xwe şunde bi evîna wan, bi xweşikîya wan ji xwe derbas bûn û ketin. Dema ku hatin ser xwe hîn di bandora evînê de bûn. Nikaribûn ji bandora wê derketana. Xanî dema behsa bandora dîtina hezkirîyan li ser wan dike; dibêje xwe girêdayî dîtin û nikaribûn bifirîyana. Li vir Xanî, Mem û Tacdîn şibandiye kevokan. Çawa ku kesek dema kevokan digire, nigê wan girêdide da ku êdî nikaribin birevin an bifirin û zengilekê bi nigê wan dixe da ku wan nas ke, bi heman şeklî jî evîna dilê wan wek benekî bû û gustîlka ku Zîn û Sitîyê kiribû destê wan jî wek zengilan, îşareta naskirinê bû. Bi vî awayî Xanî gotiye nikaribûn bifirîyana lê navê kebok an çivîkan bikar neanîye. Ev jî îstîareya girtî nîşan dide.

\section{Kînaye}

Di ferhengê de tê wateya sergirtina tiştekî bir tiştekî din. Wateya wê ya hunerî; bikaranîna bêjeyê di wateya wê ya mecazî de tevî îmkana qesdkirina wateya rast(Qezwînî, 1992, 237). Bi terîfeke din: gotina tiştekî bi awayekî sergirtî(Durmuş, 2002, 34). Kînaye di wan bêjeyan de ku xwedîyê wateya bingehîn û mecazî ne, tê bikar anîn. Eger bêjeyek di wateya xwe ya nebingehîn de were bikar anîn û di heman demê de îhtîmala ku di wateya xwe ya bingehîn de jî bikar hatibe hebe, wê demê dibe kînaye. Yanê îhtîmala du wateyan jî divê hebe.

Ev huner ji bo hinek tiştên ku bi awayekî eşkere nikarin werin gotin, tê bikar anîn. (İsen û ên din, 2016, 329) Di vê hunerê de armanca helbestvan, bi awayekî eşkere ne xuya ye û tu îşaretên ku me ji wateya eşkere bibe bi bal wateya veşartî jî nayên bikar anîn. (Değirmençay, 2014, 162)

Kînaye û mecaz nêzê hev in. Lê ferqa wan ew e ku meriv di mecazê de nikare wateya rast a peyvê bîne ber çavên xwe. Lê di kînayeyê de her du wate tên ber çavan(Cîhanî, 2013, 43). Meriv her du wateyan jî dikare bifikire ku îhtîmal heye. Em li çend mînakan binêrin:

\section{Serbendê qeseb didan cebînê}


'Aşiq dimirin ji dest evînê (420)

Xanî dema behsa xweşikîya Zîn û Sitîyê dike dibêje ku ji ber xweşikîya wan, evîndar dimirîyan. Li vir meriv dikare bibêje ku bi rastî jî evîndar dikarin ji derdê evînê bimirin. Lê li vir "mirin" di wateya mecazî de ye. Yanê evîndar ji xwe derbas dibûn û diketin bin bandora xweşikîya wan. Ji ber ku li vir "mirin" him di wateya rast de, him di wateya mecazî de dikare were fikirîn, li vir hunera kînaye heye.

\section{Da îşeve remlekê birêjim}

\section{Hetta sibe sahiban bibêjim (720)}

Reml tê wateya "xîz"ê. Xencî vê wateyê tê wateya fe'lekê ku bi riyên xwe yên taybet ji xeybê agahî tên dayîn(Bnr. Pala, 2009, 376). Di mesnewîyê de dema ku pîrik dibîne ku Zîn û Sitî evîndar in û dixwazin Mem û Tacdîn peyda kin ka li ku ne û kî ne, gustîlkan ji wan dixwaze û dibêje "Ez ê remlekê birêjim". Li vir bir rastî jî xîza maddî tê rijandin. Lê armanc ji vê rijandinê "fe'l vekirin" e. Wê demê meriv dikare bibêje ku "xîz rijandin" him di wateya rast de jî dikare were fikirîn, him di wateya duyem de wek "fe"l nihêrîn" were fikirîn. Ev jî dibe hunera kînayeyê.

\section{Binimê xwe bi suretê tebîban}

Bîperde dibînî wan hebîban (771)

"Bêperde dîtin" li vir di wateya bê astengî dîtin e. Lê dibe ku bi rastî ew dixwazin perdeya maddî ji navbera xwe vekişînin û eşkere bipeyivin û rûyê hev baş bibînin. Ji ber ku her du wate bi îmkan in, li vir hunera kînaye heye.

\section{Saqî şewişîn bi abê engîr}

\section{Mutrib 'herişîn bi seytê sentûr (930)}

Abê engûr, di wateya xwe ya yekem de ava tirî ye. Lê bi rîya kînayeyê ev ji bo şerabê tê gotin(Enverî, 1383b, 2). Ji ber ku şerab jî bi rastî ji ava tirî çêdibe. Wê demê her du wate jî dikarin mumkîn werin qebûl kirin. Meriv dikare wiha fehm bike ku "saqî dibezin da ku ava tirî bînin, an jî şerabê bînin". Ji ber îhtîmala herduyan li vir kînaye heye. Wek mînakên jor gellek mînakên din hene ku tê de wateya dualî hebe.

\section{Teşxîs}

Ev huner tê wateya "kesane kirin" an "şibandina mirovan". Yanê nîşandana heyînên xencî mirovan, wek mirovekî ku difikire, dibihîse û hereket dike. (Şener û ên din, 2014, 318) Heywanek, gulek an ba dikare bi saya vê hunerê bipeyive. Helbestvan her tiştî dikare li hember xwe wek mirovekî bibîne û pê re bipeyive an wî bide peyivandin. Dema hunera kesanekirinê/teşxîs tê xebitandin taybetiyên mirovan bo tiştên din tên dayîn û bi vî awayî wek mînak "gulek" dikare bibe "yarek". Hemû kirin, hest û taybetiyên mirovan li ser tiştên bê aqil û gîyan tên fikirîn û wek ku li hember helbestvan mirovek hebe tê tevgerîn. Ev huner jî di mesnewîyê de gellek zêde hatiye bikar anîn.

\section{Sorgul bigirîn bi eşkê şebnem}

\section{Bilbil bikenin li rexmê hemdem (307)}

Xanî di malika jor de dema behsa sedema nivîsandina Mem û Zînê dike, dibêje ku di rewşeke wisa evînî, serxweş û mest de divê ez vê berhema xwe binivîsim ku bila gul ji çavên xwe hêsiran bibarînin, bilbil li dijî nebaşîyan bikenin. Di vir de Xanî taybetîya girîn û kenîn a mirovan dide gul û bilbil.

\section{Nalan dikirin cemad $\hat{u}$ heywan}


Talan dikirin nebat $\hat{u}$ insan (418)

Xanî di destpêka mesnewîyê de behsa xweşikîya Zîn û Sitîyê dike. Delalîya wan ewqas mezin dike û pesn dide ku dibêje ev her du keçikên xweşik mîna heyv û rojê xweşik in û dema ku li çîya û bîstanan digerin, ji ber xweşikîya tiştên bêjiyan û heywan digirîn û zarî dikin. Di malika jor de cemad, di wateya tiştê wek kevir û dar bêgîyan û bêhereket e(Enverî, 1383a, 387). Bêjeya duyem jî heywan e ku ew jî nikare nalan û axîn bike. Lê Xanî taybetîya bang û nalîna mirovan daye tiştên bê aqil. Ji ber vê kesanekirin heye li vir.

\section{Geh behs dikir digel sebayê}

Şer'ha xemê dil digote bayê (1341)

Di malika jor de Xanî behsa dûrmayîna Mem ji Zînê dike. Mem bi hesret û dûrmayîna ji Zînê pir xemgîn e û ji ber vê carinan bi bayê re dipeyive û derdê dilê xwe ji bayê re vedibêje. Li vir bayê seba ango bayê sibê li hember Mem wek mirov hatiye nîşandayîn û Mem pê re dipeyive. Dibêje bila bayê seba here bal Zînê û xemgînîya Memê jê re vebêje. Guhdarîkirina axaftinê an hevpeyvîn, karê mirovan e. Lê li vir Zîn bi bayê re dipeyive û ev jî dibe hunera teşxîsê.

Ey dil! meçe bê çiraxê canî

Zulmat e tu kor î rê nizanî (1381)

Xanî li jor ji dil re dibêje ku dil bila nere, ji ber ku ew kor e û rê nizane. Dîsa di vê malikê de "çûn", "kor bûn" û "zanîn" taybetiyên mirovan in, lê ji bo dil hatine gotin.

Carinan xem, wek mirovan tevdigerin, li dor Zînê kom dibin û bi wê re rûdinin:

Zîn ma bi tenê, digel 'xeman cot

Xem lê civiyan, ji bo 'xeman got: (1256)

\section{6. Întaq}

Hunera barkirina taybetîyên mirovan li ser heywanan e(İsen û ên din, 2016, 331). Lê li vir tenê taybetîya axaftinê li ser tiştên din tê barkirin. Yanê tiştên ku qabîlîyeta wan a peyivînê tunebe, meriv bide axaftin(Olgun, 1936, 52). Helbestvan di vê hunerê de taybetîya axaftinê a mirovan dide bêgîyan û ajalan. Bi piranî teva hunera teşxîsê tê bikar anîn(Macit û ên din, 2011, 70). Ji ber ku dema meriv taybetîyeke mirovan bide tiştekî, jixwe ew tişt wek şexs û mirov tê qebûlkirin. Bi vê taybetîyê ev kar, dibe hunera teşxîsê jî. Lê eger di nav vê teşxîs û kesane kirinê de taybetîya axaftinê hebe, wê demê ev dibe teşxîs û întaq. Yanê her teşxîs ne întaq e, lê her întaq teşxîs e. Ev huner jî di gellek malikên mesnewîyê de hene. Ji ber ku li gellek cihan hevpeyvîn bi dar û beran re, bi gul û kulîlkan re, bi çem re, bi bayê sibê re, bi findê re û herwisa bi tiştinên din re heye.

\section{Pirsî ji dinê min ev bi hikmet}

\section{Mehra te çi? Gote min ku "himmet" (214)}

Di destpêka Mem û Zînê de Xanî li ser rewşa Kurdan a di nav netewên din de dike û li ser girîngîya xebatê disekine. Bi vê mebestê Xanî di malika jor de bi riya şibandinê, dinyayê wek bûkekê difikire û dide hember xwe, pê re dipeyive û jê dipirse ku mêhra wê bûkê çi ye. Pişta vê pirsê Xanî dinyayê dide axaftin û dide bersivdan ku mêhra wê xîret û hîmmet e. Di vê malikê de axaftina dinyayê, întaq e.

Şem 'ê bi zebanê hal-i bêqal

Evrengehe kir beyanê ehwal (1050) 
Dema ku daweta Sitî û Tacdînê çêdibe û gel şahîyan li dar dixe, findan li ser serê zave Tacdîn digerînin. Xanî ji bo nîşandana agirê evînê, finda ku li ser serê wî digere dide axaftin û find bi halê xwe yê germ û agirî bi Tacdîn re dipeyive û dibêje rabe here odeya bûkê. Li vir Xanî dibêje "Şem 'ê wiha beyan kir $\hat{u}$ axifi". Paşê find wek mirovan tê zimên, ango hunera întaqê derdikeve holê.

Perwaneyê go "tu xweş delîl $\hat{\imath}$ "

Şem 'ê wehe go "tu xweş xelîl $\hat{\imath}$ ” (2199)

Dema ku Mem di zindanê de ye Zîn demeke dirêj şunde tê, wî dibîne. Ev demeke gellek zor e ku bi hev re dipeyivin. Xanî van evîndaran wê demê dişêbîne pirpirok û findê. Ji ber ku di wêjeyê de jî pirpirok, evîndarê findê ye(Pala, 2009, 370). Zîn find e û Mem jî pirpirok e. Xanî ji bo axaftina wan rasterast navê pirpirok û findê dide. Wek ku ew her du peyivîbin. Axaftina pirpirok û findê hunera întaqê pêk tîne. Wekî van gelek mînakên din jî tên peyda kirin.

\section{ENCAM}

Me di vê xebatê de tenê li beşeke biçûk a hunerên wêjeyî nihêrî. Dema meriv bi vî awayî li hunerên Mem û Zînê dinêre, girîngî û cudahîya berhemê derdikeve holê. Ev hunerên mecazî hêza xeyalkarîya hunerî ya Xanî nîşan didin. Ji ber ku di van huneran de di navbera her tiştî de şibandin û têkilî çêkirin heye. Xanî her bêje, hevok û malik bi fikr û xebateke taybet nivîsandiye û xwestiye ku zimanê Kurdî bi awayekî edebî û bi asteke bilind were dîtin. Ji ber vê wî di her malikekê de çend huner bi hev re bikar anîne. Ew, li ser hunerên mecazî zêde rawestîyaye û meriv dikare bêje ku ji van hunerên mecazî jî herî zêde, hunera teşbîhê bikar anîye. Pir caran di hundirê cureyekê de jî gellek şeklên cuda yên şibandinê xebitandine. Ev jî dewlemendîya hunerî ya mesnewîyê û qabîlîyeta Xanî ya wêjeyî nîşan dide.

\section{ÇAVKANî}

Açıkgöz, Namık, Ehmedê Xanî Mem û Zîn, Ankara: T.C. Kültür Ve Turizm Bakanlığı, 2012.

Adak, Abdurrahman, Destpêka Edebiyata Kurdî, İstanbul: Weşanên Nûbiharê, 2014.

Akdemir, Hikmet, Belâgat Terimleri Ansiklopedisi, İzmir: Nil, 1999.

Aydın, Mehmet, Dilbilim El Kitabı Temel Kavramlar ve Konular, İstanbul: Akademik Kitaplar Yayınevi, 2014.

Cîhanî, Perwîz, Şîroveya Mem û Zîna Ehmedê Xanî, İstanbul: Weşanên Nûbihar, 2013.

Curr, Xelîl, Ferheg-i Erebî Farsî, Trc. Seyyid Hamîd Tebîban, Tahran: Întîşaratê Emîr Kebîr, 1373.

Çağmar, M. Edip, Alıştırmalarla Belağat, İstanbul: Ravza Yayınları, 2013.

Değirmençay, Veyis, Fünûn-ı Belağat ve Sınaat-ı Edeb̂̂, Weşanxaneya Aktif: Ankara, 2014.

Diyarbakır Büyükşehir Belediyesi. Uluslararası Ehmedê Xanî Sempozyumu, Diyarbakır: Diyarbakır Belediyesi Kültür Ve Turizm Müdürlüğü, 2008.

Durmuş, İsmail, "Kinaye", Türkiye Diyanet Vakfi İslam Ansiklopedisi, Ankara: 2002. 
Ekkawî, İn'am Fewwal, Mu'cemu'l-Mufessel fî̀ ulûmi'l-Belaxetî el-Bedî̀' wel-Beyan welMeanî, Beyrût: Darul-Kutûbu'l-İlmiyye, 1996.

Qezwînî, Xetîb, el-Îzah(Şurûhu't-telxîs), 4 Cilt, Beyrût: Daru'l-Hadî-Daru'l-Beyanu'lErebî, 1992.

Enwerî, Hasan, Ferhengê Bozorgê Soxen, 8 Cîlt, Tehran: Weşanxaneya Soxen, 1381.

Enwerî, Hasan, Ferhengê Rûzê Soxen, Tahran: Kitapxaneê Millîyê Îran, 1383a.

Enwerî, Hasan, Ferhengê Kînayatê Soxen, 2 Cîlt, Tahran: Kitapxaneê Millîyê Îran, $1383 b$.

Harbî, Abdulazîz, Belaxetul'l- Muyessere, Beyrût: Daru ibni Hazm, 2011.

Hüseynî, Abdurreşîd Abdulxafûr, Ferhengê Reşîdî, Tahran: İntişârât-i Kitapfurûşîyê Baranî, - .

İsen, Mustafa, - Horata Osman, Macit, Muhsin, - Kılıç, Filiz, - Aksoyak, İsmail Hakk1. Eski Türk Edebiyatı El Kitabı, Ankara: Grafiker Yayınları, 2016.

Kurdo, Qenatê, Tarixa Edebiyata Kurdî, Ankara: Weşanên Öz-Ge, 1992.

Külekçi, Numan, Açıklamalar ve Örneklerle Edebi Sanatlar, Ankara: Akçă̆ Yayınları, 2011.

Macit, Muhsin, - Soldan, Uğur. Edebiyat Bilgi ve Teorileri, Ankara: Weşanên Grafiker, 2011.

Musahıb, Ğulamhuseyîn, Dairet'ul-Me'arîfê Farsî, Tahran: Întîşarat-1 Emîr Kebîr, 3 Cîlt, 1380.

Olgun, Tahir, Edebiyat Lügati, İstanbul: Asar-1 İlmiye Kütüphanesi Yayınları, 1936.

Ruhullah, Hâdî, Arayehayê Edebî (Qalibhâyê Şî'r, Beyan we Bedî'), Tahran: Şirketê Çap ve Neşrê Kitaphâyê Dersîyê Îran, 1394.

Sağniç, Feqî Huseyn, Dîroka Wêjeya Kurdî, İstanbul: Enstîtuya Kurdî ya Stenbolê, 2014.

Saraç, M.A Yekta, Eski Türk Edebiyatına Giriş Söz Sanatları, Eskişehir: Anadolu Üniversitesi Yayınları, 2013.

Selçuk, Bahir, - Kesik, Beyhan, - Şenödeyici, Özer, - Koşik, H. Sercan, - Kolar, Fatman. Söz ve Sihir Arasında Edebi Sanatlar, Ankara: Kesit Yayınları, 2015.

Sefercioğlu, M. Nejat, Nev 'î Dîvânı'nın Tahlîli, Anakara: Kültür Bakanlığı, 1990.

Şener, H. İbrahim, Alim Yıldız, Türk Íslam Edebiyatı, Istanbul: Weşanên Raxbet, 2014.

Teftezanî, Mesud bin Omer, Muhteseru'l-Meanî, Beyrût: Mektebetu's-Sahabe, 2005.

Uzun, Tacettin, - Erdoğan Ayhan, - Muhammet Tasa, - Şehabettin Kırdar, - Yusuf Sami Samanc1, - Ayhan Erdoğan, - Orhan Parlak, - Latif Solmaz, - Sedat Şensoy. Anlatımlı Belagat, Konya: Elif Kitabevi, 2008. 